\title{
Mexican adolescents' risky sexual behavior and migration intentions
}

\author{
Stephanie L. Ayers \\ Arizona State University \\ Flavio F. Marsiglia \\ Arizona State University \\ Steven Hoffman \\ Brigham Young University - Provo, steven_hoffman@byu.edu \\ Jildyz Urbaeva \\ Arizona State University \\ Jaime Booth \\ Arizona State University \\ Follow this and additional works at: https://scholarsarchive.byu.edu/facpub \\ Part of the Social Work Commons
}

\section{Original Publication Citation}

Ayers, S., Marsiglia, F. F., Hoffman, S. *Urbaeva, J., \& *Booth, J. (2012). Mexican adolescents' risky sexual behavior and migration intentions. International Journal of Migration, Health, and Social Care, 8, 56-71.

\section{BYU ScholarsArchive Citation}

Ayers, Stephanie L.; Marsiglia, Flavio F.; Hoffman, Steven; Urbaeva, Jildyz; and Booth, Jaime, "Mexican adolescents' risky sexual behavior and migration intentions" (2012). Faculty Publications. 4006.

https://scholarsarchive.byu.edu/facpub/4006

This Peer-Reviewed Article is brought to you for free and open access by BYU ScholarsArchive. It has been accepted for inclusion in Faculty Publications by an authorized administrator of BYU ScholarsArchive. For more information, please contact ellen_amatangelo@byu.edu. 


\title{
Mexican adolescents' risky sexual behavior and migration intentions
}

\author{
Stephanie L. Ayers, Flavio F. Marsiglia, Steven Hoffman, Jildyz Urbaeva and Jaime Booth
}

Stephanie L. Ayers, Flavio F. Marsiglia,

Steven Hoffman,

Jildyz Urbaeva and Jaime Booth are all based at Southwest Interdisciplinary Research Center, School of Social Work, College of Public Programs, Arizona State University, Phoenix, Arizona, USA.
The research reported in this article was made possible through an international research grant awarded by the College of Public Programs at Arizona State University. Data analysis was supported by the National Institutes of Health/National Center on Minority Health and Health Disparities (P20 MD002316-04)

\begin{abstract}
Purpose - The purpose of this study is to identify the association between risky sexual behaviors and migration intentions among adolescents living in Guanajuato, Mexico.

Design/methodology/approach - Data were collected by self-administered questionnaires to students enrolled in an alternative schooling system in Guanajuato, Mexico, during the school year of 2006-2007. The sample size for this study includes 538 unmarried students, 35 percent male, ages 14-19. Ordinal logistic regression is used to estimate the odds of engaging in risky sexual behaviors.

Findings - The results reveal that male adolescents with higher intentions to migrate have significantly higher odds of engaging in risky sexual behaviors than both males who are less interested in migrating and females, regardless of their migration intentions.

Practical implications - Interventions on both sides of the US/Mexico border are needed in order to address this concern particularly among males who express a desire to migrate to the US someday.

Social implications - These findings highlight the importance of examining risky sexual behaviors even before migration to the US occurs. By engaging in high risk sexual behaviors prior to migrating, adolescents are putting themselves and both their sexual partners in Mexico and their future sexual partners in the US at increased risk of contracting STIS and HIV.

Originality/value - The study examined risky sexual behavior of adolescents in Mexico prior to migration. Knowledge about risky sexual behaviors prior to departure is vital for policy makers and researchers as they seek to design and implement interventions aimed at quelling this growing public health concern.
\end{abstract}

Keywords Mexico, Adolescents, Risky sexual behaviours, Migration intentions, Gender, Young adults, Immigrants, Sexual behaviour

Paper type Research paper

\section{Introduction}

The US/Mexico border is the longest border in the world between a developed and a developing country (McKenzie and Rapoport, 2007), resulting in a long history of migration from Mexico to the USA. According to the 2010 US Census, the Hispanic population, twothirds of which is of Mexican descent, increased by 43 percent in the last ten years, growing from 35 million in 2000 to 50 million people in 2010 (Humes et al., 2011; Pew Research Center, 2010). It is estimated that 6.6 million undocumented immigrants from Mexico resided in the USA in 2009 (Hoefer et al., 2010). Due to the increasing number of documented and undocumented individuals crossing the US/Mexico border and the transportability of diseases such as HIV/AIDS (Organista et al., 2004), public health concerns in Mexico and the USA can no longer be assessed or addressed independently.

While research has examined the risky sexual behavior of immigrants after they arrive in the USA, less is known about the sexual behaviors of adolescents in Mexico prior to migration. Research indicates that risky sexual behaviors are prevalent both during the migration process (Caballero-Hoyos et al., 2008; Duke and Gómez Carpinteiro, 2009) and after settlement in the

PAGE 56 INTERNATIONAL JOURNAL OF MIGRATION, HEALTH AND SOCIAL CARE | VOL. 8 NO. 2 2012, pp. 56-71, ๔ Emerald Group Publishing Limited, ISSN 1747-9894 DOI 10.1108/17479891211249997 
USA (Bletzer, 2004; Duke and Gómez Carpinteiro, 2009). Among Mexican migrants to the USA, low perception of risk has resulted in low condom use (Apostolopoulos et al., 2006), a greater number of sexual partners in the last year (3.3 versus 1.8) compared to non-migrating Mexican males (Magis-Rodríguez et al., 2004), and high prevalence rates of sexually transmitted infections (STIs) (Gudelia Rangel et al., 2006). While this information is helpful to understand risky sexual behaviors in the USA, understanding risky sexual behaviors prior to migration is crucial to prevention efforts, but as of yet has not been well documented. Knowledge about risky sexual behaviors prior to departure is vital for policy makers and researchers as they seek to design and implement interventions aimed at quelling this growing public health concern. Research suggests that adolescents who intend to migrate are more prone to risky behavior (Tabor and Milfont, 2011). Since traditional gender roles in Mexico impact both sexual behavior (Castañeda et al., 2001; Fernandez-Esquer et al., 2010) and migration intentions (Cerrutti and Massey, 2001; Kandel and Massey, 2002), it is important to understand how the relationship between migration intentions and risky sexual behavior may vary by gender. Therefore, the purpose of this study is to investigate the suggested connection between sexual behaviors and migration intentions among adolescents living in the state of Guanajuato, Mexico.

\section{Sexual behavior of young people in Mexico}

Risky sexual behavior is a crucial risk factor in the transmission of HIV and other STIs and is the target of many prevention efforts (CDC, 2010). Risky sexual behavior among adolescents is typically measured through three factors: age at the time of the first intercourse, number of sexual partners during a certain period of time, and use of a condom during the last intercourse (Aral, 1994; Bachanas et al., 2002; Marston and King, 2006). In Mexico, age at first sexual intercourse is, on average, between 14- and 16-years-old (Givaudan et al., 2005; Tapia-Aguirre et al., 2004). While 88 percent of 15-19 year old adolescents report having had sexual intercourse (Tapia-Aguirre et al., 2004), only 18 percent of high school students are sexually active (Givaudan et al., 2005). The Economic Commission for Latin America and the Caribbean (ECLAC) (2002) estimated the high school dropout rate in Mexico to be between 50 and 60 percent. The difference in rates between adolescents who have had sexual intercourse and those who are sexually active can be explained by higher dropout rates among sexually active youth and possibly because some adolescents abstain from sex for long periods of time after their first sexual contact. However, even one sexual experience can pose a risk to adolescent health, especially when condoms are not used. Only one-third of adolescents in Mexico report using a condom during their first sexual contact (Tapia-Aguirre et al., 2004), and the use of condoms is not consistent from one act to another by adolescents (Gutierrez et al., 2006), indicating a significant risk to Mexican youth.

\section{Gender differences in sexual behavior}

In Mexico, adolescent perceptions of safe sexual behavior can be influenced by some culturally specific social norms and expectations. Gender roles embedded in the concepts of machismo and marianismo are mirrored in the sexual behavior of many Mexican men and women. While machismo encourages males to be sexually dominant and to have multiple partners, marianismo prescribes sexual purity and submissiveness for women, and condemns having multiple partners (Fernandez-Esquer et al., 2010). For men, sexual experience before marriage is encouraged (Parrado and Flippen, 2010), and the use of verbal expressions related to sexuality represents expertise in and proof of adulthood (Szasz, 1998). Gender norms also establish that in sexual relationships men should take the role of initiator, decide on the frequency and type of relations, and to be the educator in the relationship (Castañeda et al., 2001). However, there is a growing gap between modern urban Mexico and traditional rural Mexico with regards to gender roles and the approach to relationships between men and women (Herrera, 2001). Traditional gender norms for sexual behavior are normative in rural areas of Mexico. Traditional prescriptions for femininity and masculinity have a stronger influence on attitudes towards sexual behavior among young people in rural areas. Premarital sexual activity is generally disapproved for women, and virginity is regarded as a desirable condition for marriage - a view supported by both men

VOL. 8 NO. 22012 | INTERNATIONAL JOURNAL OF MIGRATION, HEALTH AND SOCIAL CARE | PAGE 57 
and women in areas with strong influence of Catholic norms (Herrera, 1998). In urban areas, while virginity is generally not a prerequisite for marriage, young females are expected to preserve an appearance of ignorance about sexual matters (Castro-Vázquez, 2000).

Cultural norms in Mexico also influence how youth communicate with each other about contraception. Previous research has shown that both male and female adolescents are afraid to talk about contraception with their sexual partner (Pick de Weiss et al., 1991). More recent information indicates that both partners share the opinion that males should be responsible for the use of condoms, but that prevention of pregnancy is mostly a matter of female responsibility (Martinez-Donate et al., 2004). This hindrance in communication between males and females about contraception is evidenced by the lower rates of contraceptive use and higher unintended pregnancies among adolescents in Mexico than in the USA (Kessler et al., 2010). Furthermore, research on HIV transmission shows that, even when a woman is knowledgeable about HIV and suspects infidelity by her migrant spouse, adherence to traditional gender roles prohibits discussions about potential extramarital sex with their spouses, which results in low levels of safer sex strategies (Organista et al., 2004).

\section{Mexico-US migration}

Migration from Mexico to what it is now the USA has a long history of over 150 years (Canales, 2003). There are many motivations for an individual or a family to migrate, and some of those reasons have changed over time (Massey et al., 1994). In general, decision to initiate labor migration to the USA from Mexico is dictated by economic factors (Lindstrom, 1996). As migration networks mature over time and the effects of migration on households and communities become stable, new factors become important motivators for migration. The expansion of migrant networks, accumulation of social capital in receiving communities, and the spread of migratory behavior within sending communities promotes additional migration and increases the likelihood of movement across borders (Massey and Espinosa, 1997). Communities with long histories and high rates of migration have social capital available for potential migrants that reduce the risks and costs associated with the launching of the migration experience (Canales, 2003; Massey et al., 1994). Friends and relatives living and working in the USA help migrants find jobs and provide crucial support to them (Aguilera and Massey, 2003). Moreover, resources of social networks can be used for resettling into new areas (Hernández-León and Zuñiga, 2002).

\section{Gender differences in migration patterns}

Males and females in Mexico have different migration patterns which are influenced by social norms, expectations, cultural values and traditions about the role of men and women (Cerrutti and Gaudio, 2010). Numerically, males continue to lead the Mexico-US migration. According to data from the Mexican Migration Project, Mexican males are three times more likely to migrate to the USA than Mexican females (Cerrutti and Gaudio, 2010). As migratory behaviors spread through the sending community, migration expectations for males become normative. For example, in some communities of central Mexico, males who do not intend to migrate are viewed as lazy and undesirable as potential mates (Cerrutti and Massey, 2001). For young males, migration to the USA is a rite of passage and a path to adulthood that provides freedom and economic opportunities (Kandel and Massey, 2002). In general, males migrate in response to the economic needs of the family (Kanaiaupuni, 2000). Inability to provide for one's family creates anxiety and frustration among men and often leads to a decision to migrate (Guendelman, 1987).

Females have different aspirations for migration. Many Mexican females migrate to the USA to follow their families and networks. Females who migrate to the USA often do so to follow their parents (Cerrutti and Massey, 2001), to reunite with their husbands (Baker, 2004), or to migrate alongside their husbands (Cerrutti and Gaudio, 2010). They can travel on their own or with children but, in most cases; they tend to be more determined than their male counterparts to stay and to see themselves as permanent migrants (Hall et al., 2011). Because the traditional construction of gender and gender roles promotes a strict division of labor between men and women with women taking care of household and children

PAGE $58 \mid$ INTERNATIONAL JOURNAL OF MIGRATION, HEALTH AND SOCIAL CARE $\mid$ VOL. 8 NO. 22012 
(Baker, 2004; Cerrutti and Gaudio, 2010; Guendelman, 1987), migration decreases rapidly after age 24 for females (Cerrutti and Gaudio, 2010). However, the Mexican female migration experience is rapidly changing in part due to the exposure to waged-labor within Mexico and the "feminization" of the labor market within the USA (Wilson, 2006).

\section{Theoretical framework connecting migration and risky sexual behavior}

The behavior adaptation theory posits that the behavior of migrants change to resemble the patterns of behavior in the host country (Castro et al., 1996; Kessler et al., 2010; Smokowski et al., 2009a). Behaviors, norms, and attitudes are adopted by the migrating individual that fit with the host country, and as assimilation and acculturation begin, individuals start to identify with aspects of the host culture and minimize those same aspects from their culture of origin (Castro et al., 1996; Smokowski et al., 2009b). Research has suggested that Latino/a immigrants to the USA adopt health behaviors like contraceptive practices, low-fertility rates, and alcohol consumption similar to those in the USA (Caetano et al., 2000; Kessler et al., 2010; Markides et al., 1988; Myers, 2010; Rogler et al., 1991). However, the process of migration begins long before the actual migration experience takes place (Tabor and Milfont, 2011). This pre-migration acculturation has been found to be positively related to migration intentions (Kulis et al., 2008). Individuals contemplating and anticipating migration begin to examine the possibilities of leaving their home country and connecting with social networks in their destination country in preparation for migration (Tabor and Milfont, 2011). During this pre-migration acculturation, individuals familiarize themselves with the history, language, values, beliefs, behavior, and norms of the new culture (Brislin and Yoshida, 1994; Berry et al., 2006). This familiarization provides a guide for cultural appropriateness in the destination country (Brislin and Yoshida, 1994).

One way individual can begin to adopt the US behavior and familiarize with American culture during pre-migration acculturation is through the mass media (Gans, 1999). Using American mass media, immigrant adolescents cannot only learn English and obtain information about behavioral American norms, but can gain knowledge of media-portrayed American adolescent culture, particularly when their peers and parents are not able to provide this information (Louie, 2003). And, for Latino adolescents, consumption of mass media is staggering. Latino adolescents living in the USA consume, on average, 13 hours per day of mass media including: five hours of television, two hours of the internet, $1 \frac{1}{2}$ hours of video games, three hours of music, 30 minutes of print media, and 30 minutes of movies (Rideout et al., 2010). "Although [American] movies and television programs do not, and are not intended to, give an accurate picture of life in America, immigrants often learn from them and in ways not anticipated by the creators of media fare" (Gans, 1999, p. 1305). Through their exposure to mass media, permissive norms for sexual behavior are communicated to both men and woman (Hirsch et al., 2002) and can serve as a possible resource of sexual information and socialization for Mexican adolescents (Gurman, 2009). While studies have typically focused on the influence of television on sexual behaviors, the mass media, in particular television, has been found to influence risky sexual behavior among adolescents through earlier ages of sexual intercourse, increased number of sexual partners, negative attitudes towards condom use, and higher probability of teenage pregnancy (Brown et al., 2006; Chandra et al., 2008; Collins et al., 2004; Wingood et al., 2001).

In addition to the adoption of American norms and values, individuals with personality characteristics such as openness to change and sensation-seeking behaviors are more likely to emigrate (Camperio Ciani et al., 2007; Kotchick et al., 2001; Winchie and Carment, 1988). Those intending to migrate often view the immigration process as an adventure and have a high tolerance for risk (Tabor and Milfont, 2011). Undocumented migrants experience extreme risks when crossing the border which include threat of injury, and potentially loss of life (Eschbach et al., 1999). Therefore, the decision to migrate, while socially desirable, is still a risk because of the challenges of crossing the US border, leaving family and friends behind, and acculturating into a new social system. And among adolescents, engaging in one risky behavior is associated with engaging in other risk taking behaviors (Kotchick et al., 2001; Schuster et al., 1996). One example of this connection is that engaging in risky sexual

VOL. 8 NO. 22012 INTERNATIONAL JOURNAL OF MIGRATION, HEALTH AND SOCIAL CARE $\mid$ PAGE 59 
behavior is associated with engaging in delinquency and substance use among Mexican immigrant adolescents (Marsiglia et al., 2005; Santisteban et al., 2002). Like the aforementioned personality characteristics of some immigrants, engaging in risky sexual behavior may also be partially explained by a predisposition towards sensation-seeking behaviors (Kotchick et al., 2001; Neumark-Sztainer et al., 1997). Much remains to be understood about the pre-migration characteristics of youth and the factors that protect or might make them more vulnerable to unsafe sex.

\section{Hypotheses}

The purpose of this study is to examine the relationship between migration intentions and risky sexual behavior among adolescents (ages 15-19) living in a high migratory state of central Mexico and to understand how the relationship is moderated by gender. Based on previous research, traditional gender roles in Mexico, pre-acculturation and the behavior adaptation theory, it is hypothesized that:

H1. Adolescent Mexican males will be more likely than females to engage in risky sexual behavior.

H2. Mexican adolescents with high intentions to migrate to the USA will be more likely to engage in risky sexual behavior compared to those adolescents with little or no migration intentions.

H3. Adolescent Mexican males with high migration intentions will have the highest likelihood of engaging in risky sexual behavior.

\section{Methods}

The data for this study come from students enrolled in an alternative schooling system in the state of Guanajuato, Mexico during the school year of 2006-2007. The alternative schooling system, Videobachillerato (VIBA) (video high school), was intended for students who with limited financial resources could not afford traditional high school or who lived in rural or semi-rural areas and did not have access to a traditional high school. Of the 252 VIBA centers in Guanajuato, Mexico, eight were randomly selected, and 702 students completed the self-administered cross-sectional questionnaire. The questionnaire asked students about their sexual and reproductive health, current and lifetime substance use, physical and mental health status, and intentions to migrate to the USA. In addition, the questionnaires were both written and distributed in Spanish and translated into English for data analysis. With Arizona State University (ASU) IRB approval and under the leadership of the ASU research team, VIBA center's school psychologists explained the confidential, anonymous, and voluntary nature of the project. Once verbal consent was obtained from each student regarding participation, the school psychologists administered the questionnaire. Data for this study were received by ASU's research team as a de-identified database for secondary data analyses. While, the study had a 95 percent response rate, the majority of students completing the questionnaire were female (60 percent).

The lower number of males may be due historically high migration rates in Guanajuato or the higher school dropout rates of males compared to females (Massey et al., 2002). The analytic sample size for this study includes 538 students, 35 percent male, ages 14-19 that are single (e.g. not married and not cohabiting).

\section{Dependent variable}

The dependent variable, risky sexual behavior, is measured through three questions:

1. In the past three months, how many people have you had sexual relations with?

2. Last time you have sexual relations; did you or your partner use a condom?

3. Last time you had sexual relations, did you consume alcohol or use any drugs before having sex?

The final dependent variable includes three categories:

PAGE $60 \mid$ INTERNATIONAL JOURNAL OF MIGRATION, HEALTH AND SOCIAL CARE $\mid$ VOL. 8 NO. 22012 
1. (0) adolescents who were abstinent within the past three months.

2. (1) adolescents who engaged in safer sex practices within the past three months (i.e. using a condom and abstaining from alcohol/drugs during sexual intercourse).

3. (2) adolescents who engaged in risky sexual behavior in the past three months (i.e. not using a condom or using alcohol/drugs during sexual intercourse).

\section{Independent variables}

Intention to migrate to the USA was created by combining three questions:

1. "Would you like to live in the USA some day?"

2. "Would you like to work in the USA some day?"

3. "I am thinking about migrating to the USA some day."

Responses to questions (1) and (2) ranged from $1=$ not at all to $4=$ yes, a lot, while responses to question (3) ranged from $1=$ definitely not to $4=$ definitely. The mean of the items scores were calculated to create the intentions to migrate scale $(\alpha=0.786)$. Once reverse coded, intentions to migrate, a continuous variable, ranged from (1) low intentions to migrate to (4) high intentions to migrate. The adolescent's gender was measured by the question "Are you. . ? Male or Female." In this study females serve as the reference group. Finally, to assess the conditional effect of gender on intentions to migrate, an interaction term was produced by multiplying gender and intentions to migrate to create the intention to migrate-males variable. In order to properly account for multicollinearity, intention to migrate was centered.

\section{Control variables}

Control variables in this study include parental monitoring, residency in an urban area, age, socioeconomic status (SES), parent's education, and average grades in school. Parental monitoring is a mean item score $(\alpha=0.676)$ of the following questions: "How often does your dad or mom: (a) know what you do with your free time; (b) know who you hang out with; (c) ask you where you are going when you leave the house; (d) generally know what you do after school; and (e) tell you what time you need to return home." All questions ranged from $1=$ never to $4=$ always. Urban residency was defined as $1=$ living in an urban area or $0=$ living in a rural area. Age was continuous and ranged from 14 to 19. SES is a mean item score ( $\alpha=0.837$ ) of the adolescents report that "at home there is enough money to: (a) buy food; (b) buy gasoline for the car or take the bus; (c) pay utilities (electricity, water, etc.); (d) pay for school expenses; (e) buy clothing you need; (f) buy clothes you want to have; (g) do fun activities (go on vacation, go to the movies, go out)." All questions ranged from $1=$ never to $4=$ always. The highest level of parental education was determined from the adolescents' self-report of the level of education for their mother and their father. Parent education ranged from $1=$ none to $8=$ higher than preparatory school. Adolescents also self-reported their average grades in school which ranged from 1 to 4 , with an average grade of 1 equivalent to a $D$ and an average grade of 4 equivalent to an $A$.

\section{Statistical analysis}

Because the dependent variable, risky sexual behavior, includes three categories, ordinal logistic regression was employed. Ordinal logistic regression assumes that the Betas for the independent variable do not differ across categories of the dependent variable. This assumption, the proportional odds assumption, must be met in order to successfully run ordinal regression (Williams, 2007). The proportional odds assumption was tested using the Brant Test of Parallel Regression Assumption. In the final model, the global $\chi^{2}$ for the Brant Test is not significant $\left(\chi^{2}=11.48, p=0.244\right)$ and therefore the proportional odds assumption is not violated. This indicates that the independent variables do not vary across the categories for the dependent variable. In the ordinal regression model the analysis becomes a series of binary logistic regressions. Because in this study the dependent variable, risky sexual

VOL. 8 NO. 22012 | INTERNATIONAL JOURNAL OF MIGRATION, HEALTH AND SOCIAL CARE | PAGE 61 
behavior, is a three category variable (e.g. 0, 1,2), the ordinal logistic regression estimates two binary logistic regression models. The first binary logistic regression contrasts the reference group, odds of abstaining from sex within the past three months (i.e. category 0), with the odds of not abstaining from sex (i.e. categories 1 and 2). The second binary logistic regression contrasts the reference group, odds of having safer sexual behavior (i.e. categories 0 and 1), with the odds of having risky sexual behavior (i.e. category 2). Positive odds indicate that the adolescent is more likely to be in a higher category, and negative odds indicate the adolescent is more likely to be in the current or lower category (Williams, 2007). All models use Stata 10 in order to adjust for clustering at the school level (StataCorp, 2009).

\section{Results}

The descriptive statistics in Table I are presented first for the total sample and then separately for those who abstained from sex and those that did not, and for those who engaged in safer sexual behaviors and those that did not. In addition, Table I reports results of $t$-tests of mean differences by sexual behavior categories on all study variables and point to important differences both for intentions to migrate and gender. As Table I shows, for the total sample, in the past three months 87 percent of adolescents had abstained from sexual relations $(M=0.87, S D=0.33), 7$ percent had engaged in safer sexual behaviors $(M=0.07$, $\mathrm{SD}=0.25)$, and 6 percent had engaged in risky sexual behaviors $(M=0.06, \mathrm{SD}=0.23)$. Adolescents reported moderate intentions to migrate to the USA someday $(M=2.58$, $\mathrm{SD}=0.87)$. The total sample of adolescents includes 38 percent males $(M=0.38$, $\mathrm{SD}=0.48)$ and 23 percent urban residents $(M=0.23, \mathrm{SD}=0.42)$. Adolescents, on average, received high levels of parental monitoring $(M=3.35, S D=0.60)$, were 16.45 years old $(S D=1.15)$, and earned between $B$ and $C$ grades in school $(M=2.61, M=0.71)$. Parents had, on average, finished elementary school and received some junior high school education $(M=3.75, \mathrm{SD}=1.83)$ and had "almost always" had enough money to buy necessities and wants $(M=2.89, M=0.58)$. Compared to adolescents who abstained from sexual relations in the past three months, adolescents who had sexual relations had significantly higher intentions to migrate $(t=-1.96, p<0.05)$ and were significantly more likely to be males $(t=-3.44, p<0.001)$. In addition, adolescents who had sexual relations in the past three months received significantly less parental monitoring $(t=3.19, p<0.001)$, were more likely to live in an urban area $(t=-4.37, p<0.001)$, have a higher SES $(t=-1.82, p<0.10)$, and have parents whom received more formal education $(t=-2.93, p<0.05)$. These sexually

Table I Descriptive statistics for study variables, for total sample and by ordinal outcomes

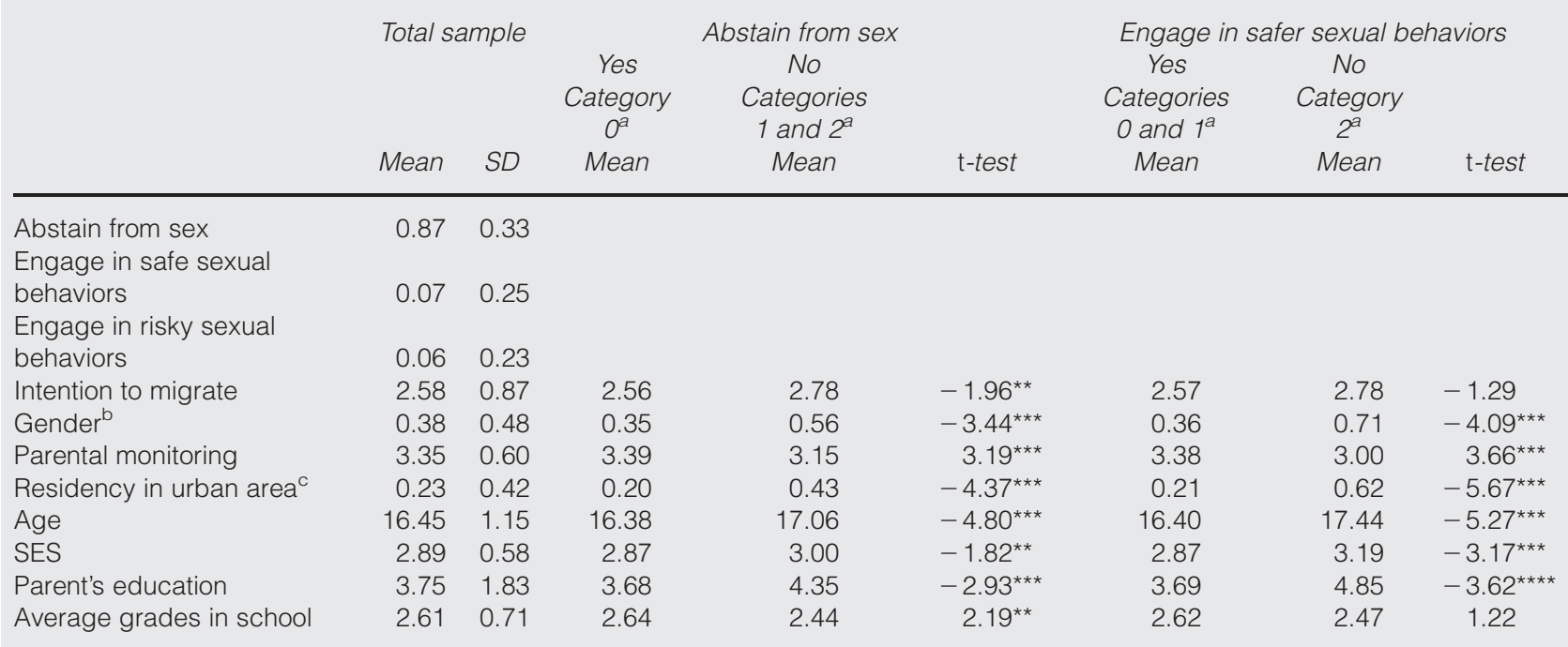

Notes: Significance at: ${ }^{*} p<0.10,{ }^{* *} p<0.05,{ }^{* * *} p<0.01,{ }^{* * * *} p<0.001$ levels; ${ }^{\mathrm{a} C a t e g o r i e s:} 0$, adolescents who were abstinent within the past three months $(n=514) ; 1$, adolescents who engaged in safer sex practices within the past three months (i.e. using a condom and abstaining from alcohol/drugs during sexual intercourse) $(n=38) ;{ }^{\text {b }}$ Mean indicates the proportion of males in each category; ${ }^{\mathrm{C}}$ Mean indicates the proportion of adolescents living in urban areas in each category

PAGE 62 | INTERNATIONAL JOURNAL OF MIGRATION, HEALTH AND SOCIAL CARE | VOL. 8 NO. 22012 
active adolescents were significantly older $(t=-4.80, p<0.001)$ and received lower grades in school (2.19, $p<0.05)$. Compared to adolescents who engaged in safer sexual behaviors in the past three months, adolescents who engaged in risky sexual behavior were significantly more likely to be male $(t=-4.09, p<0.001)$, receive less parental monitoring $(t=3.66, p<0.001)$, were more likely to live in urban areas $(-5.67, p<0.001)$, be older $(-5.27, p<0.001)$, and have higher SES $(t=-3.17, p<0.01)$ and parental education $(t=-3.62, p<0.001)$. The means for intentions to migrate to the USA, however, were not significantly different between these two groups.

Results of the ordinal logistic regression for risky sexual behavior are presented in Table II. As Model 1 shows, having higher intentions to migrate significantly increases the odds of not only engaging in sexual relations, but also engaging in risky sexual behavior (adjusted odds ratio $(A O R)=1.51, p<0.05)$. Similarly, males, compared to females, have significantly higher odds of both engaging in sexual relations and engaging in risky sexual behavior $(A O R=1.71, p<0.10)$. As parental monitoring increases, the odds of abstaining from sexual relations decreases, thus increasing the odds of engaging in risky sexual behavior $(\mathrm{AOR}=0.63, p<0.05)$. Compared to adolescents living in rural areas, adolescents residing in urban areas are twice as likely to enter into sexual relations and engage in risky sexual behavior $(\mathrm{AOR}=2.08, p<0.05)$, while older adolescents have increased odds of engaging in sexual relations and risky sexual behavior $(A O R=1.44, p<0.01)$.

In Model 2, the interaction between intentions to migrate and gender is included. The likelihood ratio test indicated a significant improvement from Model $1(\operatorname{LR}(1)=5.72$, $p<0.05)$. Although the main effect of intentions to migrate and gender were no longer significant, the interaction of gender and intentions to migrate is significant and positive, indicating that males with higher intentions to migrate have higher odds of engaging in sexual relations and in risky sexual behavior $(A O R=2.26, p<0.05)$. The direction and strength of the association between risky sexual behavior and parental monitoring, residency in an urban area, and age are similar to Model 1. The adolescent's SES, parental education, and average grades in school were not significant predictors for the odds of engaging in sexual relations or risky sexual behavior.

Figure 1 shows the effect of the intention to migrate and gender interaction on risky sexual behavior. For ease of interpretation, the figures are presented as the predicted probabilities of abstaining from sex and the predicted probabilities of engaging in risky sexual behavior. Both graphs show that for females, intentions to migrate do not moderate the association between gender and risky sexual behavior. Regardless of the level of migration intentions, females' probabilities on abstaining from sex and engaging in risky sexual behavior remain almost constant. For males, however, the effect of migration intentions is dramatic. In Figure 1(a), males who have low intentions to migrate have the highest predicted probability

Table II Ordinal logistic regression for risky sexual behavior

\begin{tabular}{lcccccc} 
& \multicolumn{3}{c}{ Model 1 } & \multicolumn{3}{c}{ Model 2 } \\
& AOR & SE & $95 \% \mathrm{Cl}$ & AOR & SE & $95 \% \mathrm{Cl}$ \\
\hline Intention to migrate & $1.51^{* *}$ & 0.28 & $1.04-2.18$ & 1.01 & 0.27 & $0.59-1.69$ \\
Gender-male & $1.71^{*}$ & 0.49 & $0.97-3.01$ & 1.46 & 0.46 & $0.78-2.71$ \\
Intention to migrate-males & & & & $2.26^{* *}$ & 0.86 & $1.07-4.77$ \\
Parental monitoring & $0.63^{* *}$ & 0.14 & $0.40-0.99$ & $0.60^{* *}$ & 0.14 & $0.38-0.94$ \\
Residency in urban area & $2.08^{* *}$ & 0.64 & $1.13-3.82$ & $2.06^{* *}$ & 0.63 & $1.14-3.75$ \\
Age & $1.44^{* * *}$ & 0.17 & $1.15-1.82$ & $1.49^{* \star *}$ & 0.18 & $1.17-1.88$ \\
SES & 1.09 & 0.25 & $0.70-1.71$ & 1.13 & 0.25 & $0.73-1.76$ \\
Parent's education & 1.06 & 0.08 & $0.91-1.24$ & 1.08 & 0.09 & $0.93-1.26$ \\
Average grades in school & 0.99 & 0.19 & $0.67-1.46$ & 1.01 & 0.19 & $0.69-1.47$ \\
Pseudo $R^{2}$ & 0.09 & & & 0.11 & & \\
Likelihood-ratio test & & & & $5.72^{* *}$ & & \\
Notes: Significance at: ${ }^{*} p<0.10,{ }^{* *} p<0.05,{ }^{* * *} p<0.01,{ }^{* * *} p<0.001$ levels; $n=538$
\end{tabular}

VOL. 8 NO. $22012 \mid$ INTERNATIONAL JOURNAL OF MIGRATION, HEALTH AND SOCIAL CARE $\mid$ PAGE 63 


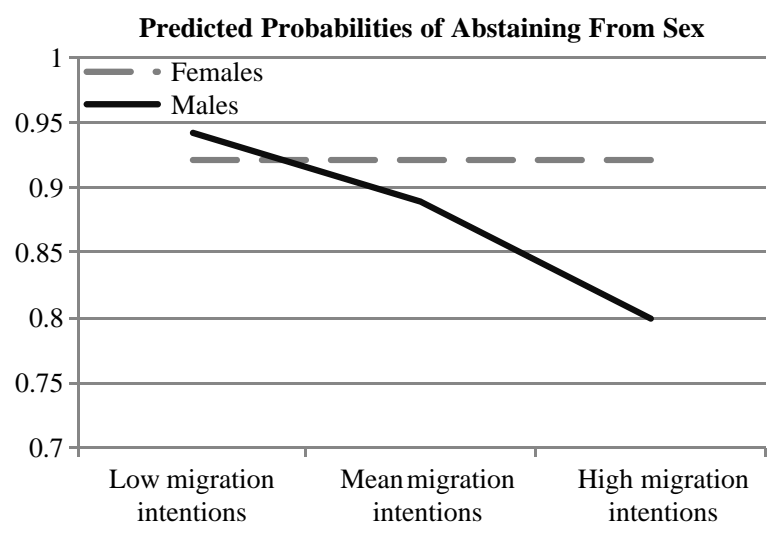

(a)

Predicted Probabilities of Engaging in Risky Sexual Behaviors

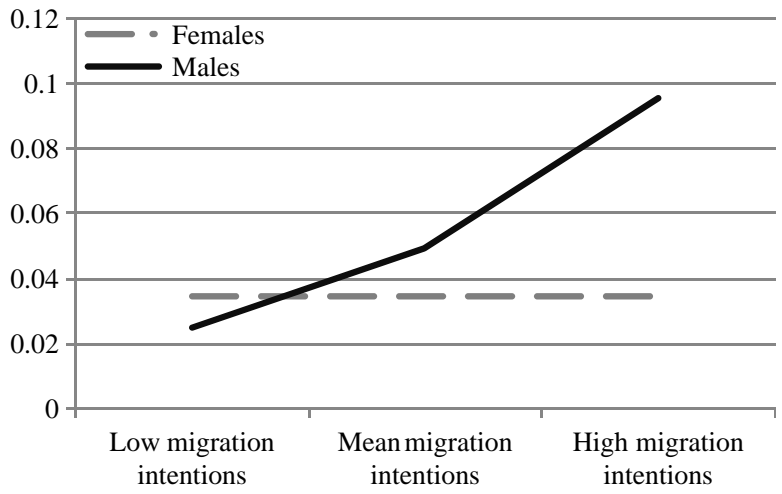

(b)

of abstaining from sexual relations in the past three months. Similarly, males who have high intentions to migrate have the highest odds of engaging in risky behaviors (Figure 1(b)).

\section{Discussion}

The results of this study support prior research on sexual behavior in Mexico and broaden our understanding of how risky sexual behavior is associated with migration intentions. As expected, males and those adolescents having intentions to migrate to the USA were more likely to engage in risky sexual behavior, supporting $\mathrm{H}_{1}$ and $\mathrm{H} 2$. New, however, and in line with $\mathrm{H} 3$, are the results suggesting that males with strong migration aspirations are more likely to engage in risky sexual behavior than both males who are less interested in migrating and females, regardless of their migration intentions. This research expands our knowledge of risky sexual behavior among adolescents in Mexico as well as how this phenomenon is impacting public health in both Mexican and the USA.

Three explanations for the connection between male migration intentions and risky sexual behavior can be readily drawn from prior research among adolescents in Mexico. The first is in line with ideas surrounding behavior adaptation theory and pre-migration acculturation (Castro et al., 1996; Hirsch et al., 2002; Kessler et al., 2010; Kulis et al., 2008; Smokowski et al., 2009a; Tabor and Milfont, 2011). Perhaps high migration aspirations have led Mexican adolescent males to become familiar with the sexual norms and behaviors of the USA and to adopt similar practices; thus, as the US media portrays permissive sexual norms as acceptable in the USA (Gans, 1999; Hirsch et al., 2002), these adolescents, in turn, accept 
that behavior as normative and engage in risky sexual behaviors. This explanation receives further support from prior studies looking at the connection between sensation-seeking personality characteristics, migration, and the undertaking of risky behaviors (Camperio Ciani et al., 2007; Kotchick et al., 2001; Tabor and Milfont, 2011). While this study did not include personality characteristics in the analysis because of dataset limitations, the results connecting migration aspirations to risky sexual behavior give further support to some of the assumptions previously made connecting personality characteristics and risky behavior.

Second, as the traditional maschismo/marianismo gender roles would suggest, males with higher levels of migration intentions are most likely to engage in risky sexual behaviors. These gendered findings support the idea that rural communities in Mexico hold strictly to the prescribed gender roles (Herrera, 2001), and that in Mexico, adolescent perceptions of safe sexual behavior are influenced by culturally specific social norms and expectations (Fernandez-Esquer et al., 2010). Indeed, the machismo traits of sexual dominance, experience in sexual matters, and engaging in sexual relations before marriage (Parrado and Flippen, 2010; Szasz, 1998), all seem to be evidenced in this sample. These gender roles surrounding sexual behavior appear to be coupled with the gender roles surrounding migration. Migration and sexual intercourse for males is seen as a rite of passage into adulthood and proof of adulthood (Kandel and Massey, 2002; Szasz, 1998). Thus, males having higher desires to migrate are impacted by two sets of gender role scripts impacting their behavior, making them more likely and more at risk for engaging in risky sexual behaviors.

The third explanation for why male migration desires are connected to sexual risk taking comes from research specific to the high migration communities of Central Mexico from which these data were drawn. As previously noted, in high migratory communities of Central Mexico male adolescents who do not intend to migrate are viewed as lazy and undesirable as potential mates (Cerrutti and Massey, 2001). So, if increased migration intentions provide more opportunities to engage in risky sexual behavior in the form of enhanced desirability, perhaps the complex pre-migration acculturation explanation can be substituted with the simple fact that boys with migration aspirations receive more attention from potential sex partners. Likewise, boys who might readily engage in risky sexual behaviors but who do not have strong migration aspirations may seem to be "safer" because of decreased opportunities for sexual companionship. While separating these three explanations makes sense from a research standpoint, it is more likely that male migration aspirations are connected with risky sexual behavior because of a combination of pre-migration acculturation behaviors, traditional gender roles, and increased sexual opportunities. Future research should focus on identifying which, if either, of these potential explanations is correct, or whether they both contribute to understanding this phenomenon.

\section{Limitations}

Due to the unique population from which these data were drawn, and the fact that this was a secondary analysis of cross-sectional data, there are various limitations that should be brought forth. First, time-ordering challenges must be noted because cause and effect conclusions cannot be made using cross-sectional data. The results of this study assume that the migration intentions of the youth have not changed either within the past three months or since the adolescent's most recent sexual encounter. However, this assumption cannot be verified; so, while unlikely, it is possible that adolescent migration intentions were actually influenced or changed since the youth's most recent risky sexual experience. Similar time ordering challenges are present for each of the control variables. Another limitation is that these findings come from participants who were selected from alternative high school programs in primarily rural locations of Guanajuato. Thus, the sample over-represents adolescents from rural and low-income families. As this study focused on the connection between migration intentions and risky sexual behavior - a topic that has not previously been approached - it is difficult to guess how the results of the study were influenced by these factors. However, it is imperative that future studies looking at this connection be done in other communities of Mexico so these results can be better understood. Finally, when studying migration intentions, it is imperative to remember that those who desire to migrate

VOL. 8 NO. 22012 | INTERNATIONAL JOURNAL OF MIGRATION, HEALTH AND SOCIAL CARE | PAGE 65 
are not always the same as those who are able to migrate. Therefore, the conclusions that assume the realization of these desires should be understood to be conditional upon migration completion.

\section{Conclusion}

The results of this study have implications for both Mexico and the USA. By engaging in risky sexual behaviors prior to migrating, adolescents are putting both their sexual partners in Mexico and their future sexual partners in the USA at increased risk of contracting STIs and HIV. Therefore, interventions on both sides of the US/Mexico border are needed in order to address this concern. Intervention efforts should focus on education. In Mexico, parents, the school, community, and religious organizations should collaborate to determine to most effective method of educating adolescents about the reality and danger of STIs and HIV. Because of the cultural gender differences, and since boys report higher levels of risky sexual behavior, there seems to be a need to gender-specific educational programs. Such programs should include information tailored to youth living in high migratory communities, and should address the influence of migration aspirations, US media, and cultural norms on risky sexual behavior.

In the USA, preventative educational efforts should target high migratory communities. Community leaders should work together to identify the most appropriate means of education new immigrants. Due to the challenges of undocumented migration, educational prevention efforts will probably be more effective through religious organizations, employers, and social service agencies than through the US educational system. However, such intervention efforts should not solely be focused on the migrants, but also those individuals within the community with whom they will come in contact. Therefore, when reaching out to individuals already living in the USA, the educational system may be the most effective means of disseminating information.

Finally, health service providers in both countries should understand how risky sexual behavior and migration aspirations are connected, and should work to educate those with STIs on how to prevent the future spread of these easily transmittable diseases. Indeed, while educational attempts to prevent infection are needed, preventing the spread of disease is an equally important challenge that should not be overlooked. As agencies and organizations in both the USA and Mexico strive to understand and prevent the spread of health problems associated with risky sexual behaviors, high-risk migrants and those living in high migratory communities will benefit from healthier and more productive lives.

\section{Implications for practice}

- Male adolescents living in Mexico with higher intentions to migrate to the USA have significantly higher odds of engaging in risky sexual behaviors. Interventions on both sides of the US/Mexico border are needed in order to address this concern.

- Prevention intervention efforts should focus on education in collaboration with parents, schools, community, and religious organizations.

- Because of the cultural gender differences there is a need for gender-specific educational programs that include information tailored to males living in high migratory communities.

- Health service providers need to understand how risky sexual behavior and migration aspirations may be connected, and should work to educate youth at risk to protect themselves from STIs and if already infected how to prevent the future spread of these easily transmittable diseases.

\section{References}

Aguilera, M.B. and Massey, D.S. (2003), "Social capital and the wages of Mexican migrants: new hypotheses and tests", Social Forces, Vol. 8, pp. 673-703.

Apostolopoulos, Y., Sonmez, S., Kronenfeld, J., Castillo, E., McLendon, L. and Smith, D. (2006), "STI/HIV risks for Mexican migrant laborers: exploratory ethnographies", Journal of Immigrant and Minority Health, Vol. 8, pp. 291-2. 
Aral, S.O. (1994), "Sexual behavior in sexually transmitted disease research: an overview", Sexually Transmitted Diseases, Vol. 21, pp. S59-S64.

Bachanas, P.J., Morris, M.K., Lewis-Gess, J.K., Sarett-Cuasay, E.J., Flores, A.L., Sirl, K.S. and Sawyer, M.K. (2002), "Psychological adjustment, substance use, HIV knowledge, and risky sexual behavior in at-risk minority females: developmental differences during adolescence", Journal of Pediatric Psychology, Vol. 27, pp. 373-84.

Baker, P.L. (2004), 'It is the only way I can survive': gender paradox among recent Mexicana immigrants to lowa", Sociological Perspectives, Vol. 47, pp. 393-408.

Berry, J.W., Phinney, J.S., Sam, D.L. and Vedder, P. (2006), "Immigrant youth: acculturation, identity, and adaptation", Applied Psychology, Vol. 55, pp. 303-32.

Bletzer, K. (2004), "Onset of substance use among transnational and domestic agricultural workers: social relations and place of initiation", Contemporary Drug Problems, Vol. 31, pp. 89-128.

Brislin, R. and Yoshida, T. (1994), Improving Intercultural Interactions: Modules for Cross Cultural Training Programs, Sage, London.

Brown, J.D., L'Engle, K.L., Pardun, C.J., Guo, G., Kenneavy, K. and Jackson, C. (2006), "Sexy media matter: exposure to sexual content in music, movies, television, and magazines predicts black and white adolescents' sexual behavior", Pediatrics, Vol. 117, pp. 1018-27.

Caballero-Hoyos, R., Torres-Lopez, T., Pineda-Lucatero, A., Navarro-Nunez, C., Fosados, R. and Valente, T.W. (2008), "Between tradition and change: condom use with primary sexual partners among Mexican migrants", AIDS and Behavior, Vol. 12, pp. 561-9.

Caetano, R., Schafer, J. and Cunradi, C.B. (2000), "Intimate partner violence, acculturation and alcohol consumption among Hispanic couples in the United States", Journal of Interpersonal Violence, Vol. 15, pp. 30-45.

Camperio Ciani, A.S., Capiluppi, C., Veronese, A. and Sartori, G. (2007), "The adaptive value of personality differences revealed by small island population dynamics", European Journal of Personality, Vol. 21, pp. 3-22.

Canales, A.I. (2003), "Mexican labor migration to the United States in the age of globalization", Journal of Ethnic and Migration Studies, Vol. 29, pp. 741-61.

Castañeda, X., Brindis, C. and Camey, I.C. (2001), "Nebulous margins: sexuality and social constructions of risks in rural areas of central Mexico", Culture, Health and Sexuality, Vol. 3, pp. 203-19.

Castro, F.G., Coe, K., Gutierres, S. and Saenz, D. (1996), "Designing health promotion programs for Latinos", in Kato, P.M. and Mann, T. (Eds), Handbook of Diversity Issues in Health Psychology, Plenum Press, New York, NY.

Castro-Vázquez, G. (2000), "Masculinity and condom use among Mexican teenagers: the Escuela Nacional Preparatoria No. 1's case", Gender and Education, Vol. 12, pp. 479-92.

CDC (2010), "Basic information about HIV and AIDS", available at: www.cdc.gov/hiv/topics/basic/ index.htm

Cerrutti, M. and Gaudio, M. (2010), "Gender differences between Mexican migration to the United States and Paraguayan migration to Argentina", The Annals of the American Academy of Political and Social Sciences, Vol. 630, pp. 93-113.

Cerrutti, M. and Massey, D.S. (2001), "On the auspices of female migration from Mexico to the United States", Demography, Vol. 38, pp. 187-200.

Chandra, A., Martino, S.C., Collins, R.L., Elliott, M.N., Berry, S.H., Kanouse, D.E. and Miu, A. (2008), "Does watching sex on television predict teen pregnancy? Findings from a national longitudinal survey of youth", Pediatrics, Vol. 122, pp. 1047-54.

Collins, R.L., Elliott, M.N., Berry, S.H., Kanouse, D.E., Kunkel, D., Hunter, S.B. and Miu, A. (2004), "Watching sex on television predicts adolescent initiation of sexual behavior", Pediatrics, Vol. 114, pp. e280-e289. 
Duke, M.R. and Gómez Carpinteiro, F.J. (2009), "The effects of problem drinking and sexual risk among Mexican migrant workers on their community of origin", Human Organization, Vol. 68, pp. 328-39.

ECLAC (2002), Social Panorama of Latin America 2001-2002, United Nations Economic Commission for Latin America and the Caribbean, Santiago de Chile, available at: www.eclac.org

Eschbach, K., Hagan, J., Rodriguez, N., Hernandez-Leon, R. and Bailey, S. (1999), "Death at the border", International Migration Review, Vol. 33, pp. 430-54.

Fernandez-Esquer, M.E., Diamond, P. and Atkinson, J. (2010), "Lazos que Atan: the influence of normative gender beliefs on sexual risk behaviors of Latino men and women", Journal of Applied Social Psychology, Vol. 40, pp. 2969-94.

Gans, H.J. (1999), Popular Culture and High Culture: An Analysis and Evaluation of Taste, Basic Books, New York, NY.

Givaudan, M., Vijver, F.J.R. and Poortinga, Y.H. (2005), "Identifying precursors of safer-sex practices in mexican adolescents with and without sexual experience: an exploratory model", Journal of Applied Social Psychology, Vol. 35, pp. 1089-109.

Gudelia Rangel, M., Martínez-Donate, A.P., Hovell, M.F., Santibáñez, J., Sipan, C.L. and Izazola-Licea, J.A. (2006), "Prevalence of risk factors for HIV infection among Mexican migrants and immigrants: probability survey in the north border of Mexico", Salud Pública de México, Vol. 48, pp. 3-12.

Guendelman, S. (1987), "The incorporation of Mexican women in seasonal migration: a study of gender differences", Hispanic Journal of Behavioral Sciences, Vol. 9, pp. 245-64.

Gurman, T.A. (2009), "Language matters: implications of sexual content in fictional narrative television programs popular among Latino adolescents", Journal of Health and Mass Communication, Vol. 1, pp. 235-57.

Gutierrez, J.P., Bertozzi, S.M., Conde-Glez, C.J. and Sanchez-Aleman, M.A. (2006), "Risk behaviors of 15-21 year olds in Mexico lead to a high prevalence of sexually transmitted infections: results of a survey in disadvantaged urban areas", BMC Public Health, Vol. 6, pp. 1-11.

Hall, M., Greenman, E. and Farkas, G. (2011), "Legal status and wage disparities for Mexican immigrants", Social Forces, Vol. 89, pp. 491-513.

Hernández-León, R. and Zuñiga, V. (2003), "Mexican immigrant communities in the south and social capital: the case of Dalton, Georgia", Southern Rural Sociology, Vol. 9, pp. 20-45.

Herrera, A.A. (1998), "Virginity in Mexico: the role of competing discourses of sexuality in personal experience", Reproductive Health Matters, Vol. 6, pp. 105-15.

Herrera, A.A. (2001), "The hybrid construction of sexuality in Mexico and its impact on sex education", Sex Education, Vol. 1, pp. 260-77.

Hirsch, J.S., Higgins, J., Bentley, M.E. and Nathanson, C.A. (2002), "The social constructions of sexuality: marital infidelity and sexually transmitted disease-HIV risk in a Mexican migrant community", American Journal of Public Health, Vol. 92, pp. 1227-37.

Hoefer, M., Rytina, N. and Baker, B.C. (2010), "Estimates of the unauthorized immigrant population residing in the United States: population estimates January 2009", available at: www.dhs.gov/xlibrary/ assets/statistics/publications/ois_ill_pe_2009.pdf

Humes, K.R., Jones, N.A. and Ramirez, R.R. (2011), "2010 census data/overview of race and hispanic origin: 2010", available at: www.census.gov/prod/cen2010/briefs/c2010br-02.pdf

Kanaiaupuni, S.M. (2000), "Reframing the migration question: an analysis of men, women, and gender in Mexico", Social Forces, Vol. 78, pp. 1311-47.

Kandel, W. and Massey, D.S. (2002), "The culture of Mexican migration: a theoretical and empirical analysis", Social Forces, Vol. 80, pp. 981-1004.

Kessler, K., Goldenberg, S.M. and Quezada, L. (2010), "Contraceptive use, unmet need for contraception, and unintended pregnancy in a context of Mexico-US migration", Field Actions Science Reports, Vol. 2, pp. 1-6.

PAGE 68 | INTERNATIONAL JOURNAL OF MIGRATION, HEALTH AND SOCIAL CARE | VOL. 8 NO. 22012 
Kulis, S., Marsiglia, F.F., Castillo, J., Becerra, D. and Nieri, T. (2008), "Drug resistance strategies and substance use among adolescents in Monterrey, Mexico", Journal of Primary Prevention, Vol. 29, pp. 167-92.

Kotchick, B.A., Shaffer, A., Miller, K.S. and Forehand, R. (2001), "Adolescent sexual risk behavior: a multi-system perspective", Clinical Psychology Review, Vol. 21, pp. 493-519.

Lindstrom, D.P. (1996), "Economic opportunity in Mexico and return migration from the United States", Demography, Vol. 33, pp. 357-74.

Louie, J. (2003), "Media in the lives of immigrant youth", New Directions for Youth Development, Vol. 2003, pp. 111-30.

McKenzie, D. and Rapoport, H. (2007), "Network effects and the dynamics of migration and inequality: theory and evidence from Mexico", Journal of Development Economics, Vol. 84, pp. 1-24.

Magis-Rodríguez, C., Gayet, C., Negroni, M., Leyva, R., Bravo-García, E., Uribe, P. and Bronfman, M. (2004), "Migration and AIDS in Mexico: an overview based on recent evidence", Journal of Acquired Immune Deficiency Syndromes, Vol. 37, pp. S215-S226.

Markides, K., Krause, N. and Mendes de Leon, C.F. (1988), "Acculturation and alcohol consumption among Mexican Americans: a three-generation study", American Journal of Public Health, Vol. 78, pp. 1178-81.

Marsiglia, F.F., Kulis, S., Wagstaff, D.A., Elek, E. and Dran, D. (2005), "Acculturation status and substance use prevention with Mexican and Mexican American youth", Journal of Social Work Practice in the Addictions, Vol. 5, pp. 85-111.

Marston, C. and King, E. (2006), "Factors that shape young people's sexual behaviour: a systematic review", The Lancet, Vol. 368, pp. 1581-6.

Martinez-Donate, A.P., Hovell, M.F., Blumberg, E.J., Zellner, J.A., Sipan, C.L., Shillington, A.M. and Carrizosa, C. (2004), "Gender differences in condom-related behaviors and attitudes among Mexican adolescents living on the US-Mexico border", AIDS Education and Prevention, Vol. 16, pp. 172-86.

Massey, D.S. and Espinosa, K.E. (1997), "What's driving Mexico-US migration? A theoretical, empirical, and policy analysis", American Journal of Sociology, Vol. 102, pp. 939-99.

Massey, D.S., Durand, J. and Malone, N. (2002), Beyond Smoke and Mirrors: Mexican Immigration in an Era of Economic Integration, Russell Sage, New York, NY.

Massey, D.S., Arango, J., Hugo, G., Kouaouci, A., Pellegrino, A. and Taylor, J.E. (1994), "An evaluation of international migration theory: the North American case", Population and Development Review, Vol. 20, pp. 699-751.

Myers, S.M. (2010), "Connecting the demographic dots: geographic mobility and birth intentions", Journal of Family Issues, Vol. 31, pp. 1622-51.

Neumark-Sztainer, D., Story, M., French, S.A. and Resnick, M.D. (1997), "Psychosocial correlates of health compromising behaviors among adolescents", Health Education Research, Vol. 12, pp. 37-52.

Organista, K.C., Carrillo, H. and Ayala, G. (2004), "HIV prevention with Mexican migrants: review, critique, and recommendations", Journal of Acquired Immune Deficiency Syndromes, Vol. 37, pp. S227-S239.

Parrado, E.A. and Flippen, C.A. (2010), "Migration and sexuality: a comparison of Mexicans in sending and receiving communities", Journal of Social Issues, Vol. 66, pp. 175-95.

Pew Research Center (2010), "Hispanics of Mexican origin in the United States, 2008", available at: http://pewhispanic.org/files/factsheets/59.pdf

Pick de Weiss, S., Atkin, L.C., Gribble, J.N. and Andrade-Palos, P. (1991), "Sex, contraception, and pregnancy among adolescent in Mexico City", Studies in Family Planning, Vol. 22, pp. 74-82.

Rideout, V.J., Foehr, U.G. and Roberts, D.F. (2010), "Generation M²: media in the lives of 8-to-18-year-olds", available at: www.kff.org/entmedia/mh012010pkg.cfm

VOL. 8 NO. 22012 | INTERNATIONAL JOURNAL OF MIGRATION, HEALTH AND SOCIAL CARE | PAGE 69 
Rogler, L.H., Cortes, R.S. and Malgady, R.G. (1991), "Acculturation and mental health status among Hispanics", American Psychologist, Vol. 46, pp. 585-97.

Santisteban, D.A., Muir-Malcolm, J.A., Mitrani, V.B. and Szapocznik, J. (2002), "Integrating the study of ethnic culture and family psychology intervention science", in Liddle, H., Levant, R., Santisteban, D.A. and Bray, J. (Eds), Family Psychology: Science-based Interventions, American Psychological Association, Washington, DC.

Schuster, M.A., Bell, R.M. and Kanouse, D.E. (1996), "The sexual practices of adolescent virgins: genital sexual activities of high school students who have never had vaginal intercourse", American Journal of Public Health, Vol. 86, pp. 1570-6.

Smokowski, P.R., David-Ferdon, C. and Stroupe, N. (2009a), "Acculturation and violence in minority adolescents: a review of the empirical literature", Journal of Primary Prevention, Vol. 30, pp. 215-63.

Smokowski, P.R., Rose, R.A. and Bacallao, M. (2009b), "Acculturation and aggression in Latino adolescents: modeling longitudinal trajectories from the Latino Acculturation and Health Project", Child Psychiatry and Human Development, Vol. 40, pp. 589-608.

StataCorp (2009), Stata Statistical Software: Release 10, StataCorp LP, College Station, TX.

Szasz, I. (1998), "Masculine identity and the meanings of sexuality: a review of research in Mexico", Reproductive Health Matters, Vol. 6, pp. 97-104.

Tabor, A.S. and Milfont, T.L. (2011), "Migration change model: exploring the process of migration on a psychological level", International Journal of Intercultural Relations, Vol. 85, pp. 818-32, available at: www.sciencedirect.com/science/article/pii/S0147176710001306

Tapia-Aguirre, V., Arillo-Santillán, E., Allen, B., Angeles-Llerenas, A., Cruz-Valdéz, A. and Lazcano-Ponce, E. (2004), "Associations among condom use, sexual behavior, and knowledge about HIV/AIDS: a study of 13,293 public school students", Archives of Medical Research, Vol. 35, pp. 334-43.

Williams, R. (2007), "Generalized ordered logit/partial proportional odds models for ordinal dependent variables", available at: www.nd.edu/ rwilliam/gologit2/gologit2.pdf

Wilson, T.D. (2006), "Strapping the Mexican woman immigrant: the convergence of reproduction and production”, Anthropological Quarterly, Vol. 79, pp. 295-302.

Winchie, D.B. and Carment, D.W. (1988), "Intention to migrate: a psychological analysis", Journal of Applied Social Psychology, Vol. 18, pp. 727-36.

Wingood, G.M., DiClemente, R.J., Harrington, K., Davies, S., Hook, E.W. and Oh, M.K. (2001), "Exposure to X-rated movies and adolescents' sexual and contraceptive-related attitudes and behaviors", Pediatrics, Vol. 107, pp. 1116-9.

\section{About the authors}

Stephanie L. Ayers is the Coordinator of Research at the Southwest Interdisciplinary Research Center, a national exploratory center of excellence funded by the National Institute on Minority Health and Health Disparities (NIMHD) of the National Institutes of Health (NIH), at Arizona State University. Her research focuses on racial and ethnic disparities in health. She examines how the constructs of culture influence substance use prevention of Mexican heritage and American Indian adolescents living in the Southwest, and the design and testing of effective prevention programs for ethnic minority populations. Stephanie L. Ayers is the corresponding author and can be contacted at: stephanie.I.ayers@asu.edu

Flavio F. Marsiglia is a member of the faculty of the Arizona State University School of Social Work where he is the Distinguished Foundation Professor of Cultural Diversity and Health. He is the director of the Southwest Interdisciplinary Research Center (SIRC), a national exploratory center of excellence funded by the National Institute on Minority Health and Health Disparities (NIMHD) of the National Institutes of Health (NIH). In addition, Dr Marsiglia is the Principal Investigator of other research projects studying risk and protective factors associated with health outcomes among ethnic minority youth and their families. His areas of specialization are health disparities research, drug abuse, HIV/AIDS prevention and culturally grounded social work practice with an emphasis on Latino cultures. He is also actively involved in several international research projects in Mexico, Spain and Tanzania.

PAGE 70 | INTERNATIONAL JOURNAL OF MIGRATION, HEALTH AND SOCIAL CARE | VOL. 8 NO. 22012 
Steven Hoffman graduated from Arizona State University with his PhD in 2011. He is currently working as a research associate with the Southwest Interdisciplinary Research Center, a national exploratory center of excellence funded by the National Institute on Minority Health and Health Disparities (NIMHD) of the National Institutes of Health (NIH). His areas of interest are mental health disparities, adolescent emotional and behavioral health, and religiosity.

Jildyz Urbaeva is a social work PhD student at the Arizona State University. Her research interests include health disparities, particularly in the area of reproductive health, in developing countries.

Jaime Booth is a second year PhD student in the School of Social Work at Arizona State University and a research assistant at the Southwest Interdisciplinary Research Center. Her research focuses on social determinate of mental health disparities. While working at the center she has participated in several projects that examine how culture impacts health outcomes and can be integrated into effective prevention programming.

To purchase reprints of this article please e-mail: reprints@emeraldinsight.com Or visit our web site for further details: www.emeraldinsight.com/reprints 
Reproduced with permission of the copyright owner. Further reproduction prohibited without permission. 